\title{
Assessment of the Potential Role of Silymarin Alone or in Combination with Vitamin $E$ and/ or Curcumin on the Carbon Tetrachloride Induced Liver Injury in Rat
}

\author{
Nouf Al-Rasheed ${ }^{1}$, Laila Faddah $^{1}$, Iman A Sharaf ${ }^{2,3^{*}}$, Azza M Mohamed ${ }^{2,4}$, Nawal Al- \\ Rasheed $^{1}$ and Nayira Abdelbaky ${ }^{1}$ \\ ${ }^{I}$ Faculty of Pharmacy-Pharmacology Department; King Saud University; Riyadh - Saudi Arabia. ${ }^{2}$ Faculty of \\ Science; ALFaisaliah Campus; Biochemistry Department; King Abdulaziz University; Jeddah - Saudi Arabia. \\ ${ }^{3}$ Medical Research Institute; Biochemistry Department; Alexandria University; Alexandria - Egypt. ${ }^{4}$ Theraputic \\ Chemistry Department; National Research Center; Dokki - Egypt
}

\begin{abstract}
The aim of this study was to investigate the effective role of silymarin either alone or in a combination with vitamin $E$ and/or curcumin against the toxic impact of carbon tetrachloride (CCl4) induced liver injury The results revealed that administration of silymarin alone or in a combination with vitamin $E$ and/or curcumin for 21 consecutive days, $24 \mathrm{~h}$ after CCl4 injection to rats, markedly ameliorated DNA damaged and apoptosis markers in rat livers, proinflammatory markers including tumor necrosis factor- $\alpha(T N F-\alpha)$ and $C$-reactive protein $(C R P)$ in rat livers

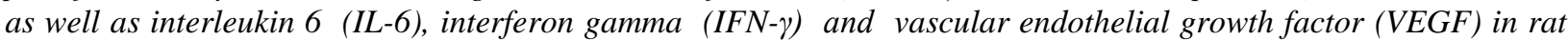
sera. These treatments also could ameliorated the alteration in cytochrome P450 2E1 (CYP2E1) activity in livers of CCl4 intoxicated rats as well as the increase in the serum alanine aminotransferase (ALT) compared with CCl4 intoxicated untreated rats. The present biochemical results are supported by histo-pathological examination. In conclusion, silymarin in a combination with vitamin $E$ and curcumin was the most effective treatment in alleviating CCl4 induced liver damage and this may support the use of this combination as an effective treatment against liver damage induced by toxic agents.
\end{abstract}

Key words: Silymarin, Vitamin E, Curcumin, Carbon Tetrachloride

\section{INTRODUCTION}

Liver diseases are mainly caused by toxic chemicals, excess of alcohol consumption, infections and autoimmune disorders. Liver damage caused by drugs and toxins may mimic all forms of acute and chronic liver diseases. Carbon tetrachloride continues to be one of the most commonly used toxins in the experimental studies of liver diseases. CCl4-induced hepatotoxicity through two phases. The initial phase involves the metabolism of $\mathrm{CCl} 4$ by cytochrome $\mathrm{P} 450$ to the trichloromethyl radicals ( $\mathrm{CCl} 3 \bullet$ and/or $\mathrm{CCl} 3 \mathrm{OO})$, which lead to membrane lipid peroxidation and finally to cell necrosis (Manibusan et al.2007). The second phase of CCl4-induced hepatotoxicity involves the activation of Kupffer cells, which is accompanied by the production of proinflammatory mediators (Planagum et al. 2005). On the other hand, the toxicity of $\mathrm{CCl} 4$ has been attributed to one of several possible mechanisms, viz., covalent metabolite binding, lipid peroxidation, reactive aldehydes, nucleic acid hypomethylation, loss of calcium

*Author for correspondence: elsadat1956@yahoo.com 
homeostasis, or inflammatory cytokines, consensus has emerged that $\mathrm{CCl} 4$ toxicity is a multifactorial process to which any of the above quoted mechanisms contribute .

The implication of oxidative stress and inflammation in the etiology and progression of several acute and chronic clinical disorders has led to the suggestion those agents with antioxidant and anti-inflammatory properties may have health benefits (Weber et al. 2003).

In the present study, silymarin and two potent antioxidants, including vitamin $\mathrm{E}$ and curcumin, have been selected to evaluate their potential therapeutic effect against liver damaged induced by $\mathrm{CCl} 4$.

Silymarin is a commonly used herbal therapy, particularly by patients who have liver disease, where it resulted in reducing serum bilirubin, and transaminases (Wellington and Jarvis 2001) This hepatoprotective effect of silymarin has been suggested to result from membrane-stabilizing, free radicals scavenging properties (Muriel and Mourelle 1990) inhibition of lipid peroxidation (Flora et al. 1998) and modulation of hepatocyte $\mathrm{Ca}++$ (Farghali et al. 2000).

Vitamin $\mathrm{E}$ is a natural component of the membrane lipid bilayer (Lee; East and Balgaug 1991). Subsequently, vitamin $E$ is a potent lipid soluble antioxidant in biological systems with the ability to directly quench free radicals and function as a membrane stabilizer. In addition, vitamin $\mathrm{E}$ controls lipid peroxidation by limiting the propagation of chain reaction in biological systems (Kalender et al. 2005). Curcumin (1, 7-bis (4-hydroxy-3-methoxyphenyl)-1,6-heptadiene-

3,5-dione) is a natural yellow pigment originally isolated from turmeric (Curcuma longa L.), a rhizome used as a spice and medicinal agent. It possesses a wide range of pharmacological properties. Curcumin was shown to inhibit inflammatory processes and to act as an antioxidant (Naik et al._2004). Research has shown curcumin to be a powerful scavenger of the superoxide anion, the hydroxyl radical and nitrogen dioxide (Daniel et al. 2004).

This study was designed to investigate the potential impact of silymarin either alone or in combination with Vitamin $\mathrm{E}$ and/or curcumin on liver damage induced by inflammation, oxidative DNA damage and apoptosis in response to $\mathrm{CCl} 4$ toxicity in rats.

\section{MATERIAL AND METHODS}

\section{Chemicals}

All reagents used were of high analytical grade, product of Sigma and Merck companies. Silymarin, curcumin and vitamin E were obtained from Sigma Chemical Co. (Sigma, St. Louis, MO, USA).

\section{Animals and treatments}

Sixty healthy male albino rats $(120-150 \mathrm{~g})$ of Sprague-Dawley strain, were obtained from the Experimental Animal Center, Faculty of Pharmacy, King Saud University, Saudi Arabia, and Riyadh. The animal experimental protocol was approved by the Animal Care and Ethical Committee of Faculty of Pharmacy, King Saud University. Animals were housed in clean acrylic cages and maintained under standard conditions (12-h light/12-h dark cycle) with a controlled temperature of 20 to $22^{\circ} \mathrm{C}$ and humidity of $60 \%$. Rats were fed a standard rat pellet diet with free access to tap water ad libitum for 1 week for acclimatization. After 1 week of acclimation, the rats were made to fast overnight before treatment and were divided randomly into six groups, each of ten rats as follows:

Group 1: Normal healthy control rats

Group 2: CCl4-intoxicated rats.

Group 3:CCl4 intoxicated rats treated with silymarin alone.

Group 4:CCl4 intoxicated rats treated with silymarin and vitamin $\mathrm{E}$.

Group 5:CCl4 intoxicated rats treated with silymarin and curcumin.

Group 6:CCl4 intoxicated rats treated with a combination of silymarin, vitamin $\mathrm{E}$ and Curcumin.

A single dose of $\mathrm{CCl} 4$ was injected intraperitoneally to the rats as a mixture of corn oil and $\mathrm{CCl} 4(1: 1,1 \mathrm{ml} / \mathrm{kg}$ body weight, $0.5 \mathrm{ml}$ CCl4+ $0.5 \mathrm{~mL}$ corn oil) (Yachi et al. 2010). Silymarin (200mg/Kg/day) ( $\mathrm{Li}$ et al. 2012) vitamin E (50 mg/Kg/day) (Karima 2007) and curcumin $(100 \mathrm{mg} / \mathrm{Kg} /$ day $)$ were orally given daily for 21 days, $24 \mathrm{~h}$ after $\mathrm{CCl} 4$ administration (Sreepriya and Bali 2006) Twenty two days later, arterial blood samples were collected. Serum was separated by centrifugation at $3000 \mathrm{rpm}$ for 10 min and used for biochemical serum analysis.

After blood collection, the rats of each group were sacrificed under ether anesthesia, and their liver 
tissue samples were collected, weighed and washed using chilled saline solution. The liver samples were minced and homogenized in icecold bi-distilled water to yield $10 \%$ homogenates. The homogenates were centrifuged for $15 \mathrm{~min}$ at $4000 \mathrm{rpm}$ at $4 \mathrm{C}^{0}$, and the supernatants were used for biochemical tissue analysis. Four liver samples from each group were kept in $10 \%$ formalin for Histopathological examination.

\section{Biochemical assay of liver tissue}

The comet assay, or single cell gel electrophoresis, is a widely used technique for measuring and analyzing DNA breakage in individual cells. The method of Singh et al. (1988)' which involves the unwinding of DNA under alkaline conditions, was used in this study. At least fifty cells from liver per sample were submitted to analysis. The liver cells were enzymatically isolated using collagenase digestion. The parameters measured to analyze the electrophoretic patterns were the tail length and the relative DNA content in the tail. The tail moment was defined by the percentage of DNA in the tail multiplied by the length between the center of the head and tail which was defined by Olive et al. (1990).

Caspase-3-like protease was assayed according to the method described by Vaculova and Zhivotovsky (2008). For analysis of 8Hydroxydeoxyguanosine ( $8-\mathrm{OHdG}$ ) formation, the DNA was extracted from the nuclear fraction with the DNA Extractor WB Kit (Asami et al.1996) To the extracted nuclear DNA ( 100 $\mathrm{mg} / 100 \mathrm{~mL}$ of $0.1 \mathrm{mM}$ EDTA), $1 \mu \mathrm{L}$ of $2 \mathrm{M}$ sodium acetate, $4 \mu \mathrm{L}$ of nuclease $\mathrm{P} 1(5 \mathrm{mg} / \mathrm{mL}$, Yamasa Co., Japan, YA7801) and $2 \mu \mathrm{L}$ of acid phosphatase $(47 \mathrm{mg} / \mathrm{mL}$, suspension in $1.8 \mathrm{M}$ (NH4)2SO4, Sigma, P-1435) were added and incubated at $37^{\circ} \mathrm{C}$ for $30 \mathrm{~min}$. The $8-\mathrm{OH}-\mathrm{dG}$ content in the digested DNA was measured by an HPLC-ECD systems, as described previously (Nakaeet al.1995).TNF- $\alpha$ was measured using the ELISA assay Kit following the instructions supplied by the manufacturer (DuoSet kits; R\&D Systems, Minneapolis, MN, USA). C-reactive protein (CRP) was estimated by immunonephelometric (Dade Behring N Latex High Sensitivity CRPTM mono assay) on a Behring Nephelometer II analyzer. In this method, polystyrene beads coated with rat monoclonal antibodies bind to serum CRP forming aggregates. The intensity of the scattered light is directly proportional to CRP concentration. Cytochrome P450 2E1 (CYP2E1) activity was measured by Hydroxylation of $p$-nitrophenol to 4-nitrocatechol, a reaction catalyzed specifically by CYP2E1, was determined calorimetrically. Liver tissue was homogenized in $0.15 \mathrm{KCl}$ and was spun at $10,000 \times g$ for $30 \mathrm{~min}$. Microsomes were isolated by further centrifugation at $105,000 \times g$ for $60 \mathrm{~min}$. For the assay, $300 \mu \mathrm{L}$ of microsomal protein was incubated for $5 \mathrm{~min}$ at $37^{\circ} \mathrm{C}$, and absorbance at $535 \mathrm{~nm}$ was measured with 4-nitrocatechol as a standard. The CYP2E1-catalyzed $p$-nitrophenol hydroxylation was expressed as Nano moles of product formed per minute per milligram of microsomal protein.

\section{Biochemical serum analysis:}

Serum alanine aminotransferase activity was measured calorimetrically using a diagnostic kit (Procedure No. 505, Sigma Chemical Co., St Louis, MO) according to the instructions provided.

The concentration of INF- $\gamma$, was estimated using a rat sandwich ELIZA kit (Thermo Fisher Scientific Inc., USA) according to manufacturer's instructions. IL-6 was measured using a high sensitive rat ELISA kit (IBL International $\mathrm{GmbH}$, Flughafenstr, Hamburg, Germany) following the instructions of the manufacture. The level of VEGF was assayed by calorimetric, quantitative, sandwich ELISA (R\&D Systems, UK) at $492 \mathrm{~nm}$, following the manufacturer's instructions. VEGF content was estimated using a standard curve generated with specific standards provided by the manufacture

\section{Histopathological examination}

A small pieces of liver were fixed by $10 \%$ neutral buffer formalin $0.1 \mathrm{M}$ phosphate buffer $(\mathrm{pH} 7.4)$ and then embedded into paraffin, sectioned for 5$6 \mu \mathrm{m}$ thick, and mounted on the glass microscope slides using standard histopathological techniques. The sections were stained with Masson's trichrome stain and examined by light microscopy.

\section{Statistical analysis}

The data were represented as mean \pm SD. Results were analyzed by comparing the values of various experimental groups with the values of normal and toxicated untreated groups. Significant differences among different groups were analyzed using one-way analysis of variance (ANOVA) followed by Bonferroni's test. 


\section{RESULTS}

The effects of silymarin alone or in a combination with vitamin $\mathrm{E}$ and/or curcumin on the markers of DNA damage, namely $\%$ tailed, tail Length, DNA $\%$ in the tail, 8HDG as well as on the apoptosis biomarker, caspase-3, in liver tissues of $\mathrm{CCl} 4$ intoxicated rats are shown in Table 1.
The toxicity of $\mathrm{CCl} 4$ induced pronounced increases in all the above biomarkers compared with the normal animals $(\mathrm{P}<0.001)$, and the intake of either silymarin alone or in a combination with vitamin $\mathrm{E}$ and/or curcumin, significantly down-modulated the deviation in these markers versus $\mathrm{CCl} 4$ intoxicated group. $(\mathrm{P}<0.001)$.

Table 1 - Effect of silymarin alone or in combination with Vit E and/or Curcumin on markers of DNA damage in liver tissues of $\mathrm{CCl} 4$ intoxicated rats.

\begin{tabular}{lccccc}
\hline Groups & \% tailed & $\begin{array}{c}\text { Tail Length } \\
(\boldsymbol{\mu m})\end{array}$ & $\begin{array}{c}\text { DNA \% in the } \\
\text { tail }\end{array}$ & $\begin{array}{c}\text { 8HDG } \\
(\mathbf{n g} / \mathbf{1 0 0 m g} \\
\text { liver tissue) }\end{array}$ & $\begin{array}{c}\text { Caspase-3 } \\
(\mathbf{n g} / \mathbf{1 0 0 m g} \text { protein) }\end{array}$ \\
\hline Control & $4 \pm 1.14$ & $1.55 \pm 0.07$ & $1.59 \pm 0.01$ & $150.1 \pm 7.6$ & $159 \pm 2.6$ \\
CCL $_{4}$ & $23.5 \pm 2.12^{\mathrm{a}}$ & $6 \pm 0.14^{\mathrm{a}}$ & $5.97 \pm 0.43^{\mathrm{a}}$ & $332.8 \pm 19.9^{\mathrm{a}}$ & $197.8 \pm 6.4^{\mathrm{a}}$ \\
Sil & $16.50 \pm 2.12^{\mathrm{a}^{* \# \#}}$ & $3.55 \pm 0.07^{\mathrm{a}^{* \#}}$ & $3.34 \pm 0.04^{\mathrm{a}^{* \# \#}}$ & $186.3 \pm 6.2^{\mathrm{a}^{*}}$ & $166.3 \pm 6.3^{*}$ \\
Sil + V.E & $13.50 \pm 0.70^{\mathrm{b}^{*}}$ & $3.45 \pm 0.07^{\mathrm{a}^{* \#}}$ & $3.17 \pm 0.16^{\mathrm{b}^{*}}$ & $185.5 \pm 4.2^{\mathrm{b}^{*}}$ & $158.3 \pm 2.6^{*}$ \\
Sil + Cur & $15.01 \pm 0.01^{\mathrm{a}^{*}}$ & $3.39 \pm 0.04^{\mathrm{a}^{* \#}}$ & $3.07 \pm 0.06^{\mathrm{b}^{*}}$ & $179 \pm 6.2^{\mathrm{b}^{*}}$ & $159.3 \pm 6.3^{*}$ \\
Sil + V.E + Cur & $11 \pm 1.14^{\mathrm{c}^{*}}$ & $2.69 \pm 0.01^{\mathrm{a}^{*}}$ & $2.69 \pm 0.09^{\mathrm{c}^{*}}$ & $174.8 \pm 1.9^{\mathrm{c}^{*}}$ & $156.3 \pm 1.5^{*}$ \\
\hline
\end{tabular}

Values are means \pm S.D $(n=10)$. ${ }^{a} \mathrm{P}<0.001$, bP $<0.01$ and ${ }^{c} \mathrm{P}<0.05$ compared to normal control group, $* \mathrm{P}<0.001$ compared to $\mathrm{CCl} 4$ intoxicated group, ${ }^{\#} \mathrm{P}<0.001$ and ${ }^{\# \#} \mathrm{P}<0.05$ compared to Sil+V.E.+Cur group, respectively, using ANOVA followed by Tukey-Kramer as post ANOVA test.

As shown in Figure 1, the levels of the proinflammatory markers, TNF- $\alpha$ and CRP, were significantly elevated by $\mathrm{CCl} 4$ injection in rat liver tissues compared with the animals in the control group. Administration of silymarin only, or in a combination with vitamin $\mathrm{E}$ or curcumin to $\mathrm{CCl} 4$

A

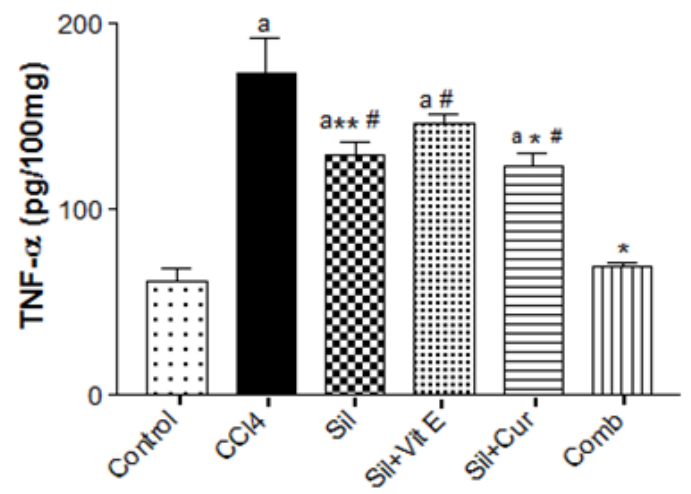

intoxicated rats, successfully reduced the levels of TNF- $\alpha$ and CRP compared with $\mathrm{CCl} 4$ intoxicated untreated animals. However, the combination of the three agents caused restoration of the inflammatory markers near to the level of normal control .

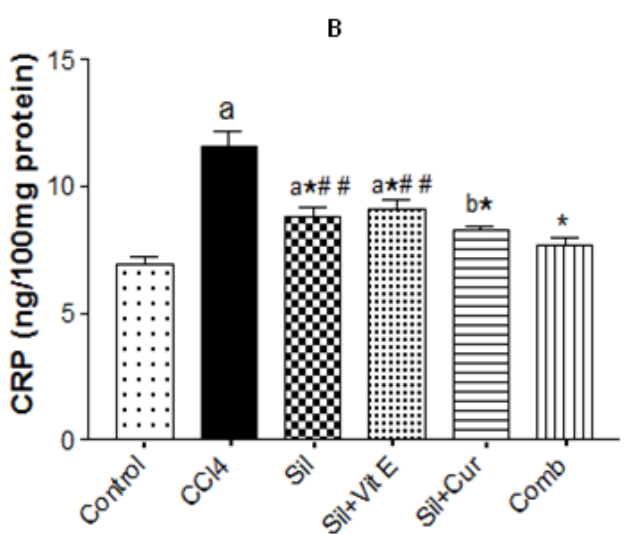

Figure 1 - Effect of silymarin alone or in a combination with Vit E and/or curcumin on TNF- $\alpha(\mathrm{A})$ and CRP (B) levels in liver tissues of CCl4-intoxicated rats. Values are mean \pm S.D $(n=10)$. ${ }^{a} \mathrm{P}<0.001$ and ${ }^{\mathrm{b}} \mathrm{P}<0.01$ compared to normal control group, $* \mathrm{P}<0.001$ and $* * \mathrm{P}<0.01$ compared to CCl4-intoxicated group, ${ }^{\#} \mathrm{P}<0.05$ and ${ }^{\#} \mathrm{P}<0.001$ compared to Sil+Vit E+Cur (Comb) group, respectively, using ANOVA followed by Tukey-Kramer as post ANOVA test.

Figure 2 showed that marked increases in the as well as in the level of angiogenic marker, levels of inflammatory markers, IL-6, and IFN- $\gamma$, VEGF, in the sera of rats intoxicated with $\mathrm{CCl} 4$ 
with respect to control ones. Intake of silymarin only, or in a combination with vitamin $\mathrm{E}$ and /or curcumin to $\mathrm{CCl} 4$ intoxicated rats, markedly down regulated the levels of these biomarkers compared with $\mathrm{CCl} 4$ intoxicated rats.

Figure 3 demonstrated that, intoxication of rats with $\mathrm{CCl} 4$, significantly reduced the level of $\mathrm{P} 4502 \mathrm{E} 1$ in their livers in relation to normal rats $(\mathrm{P}<0.001)$. Administration of silymarin alone or in a combination with vit $\mathrm{E}$ and/or curcumin effectively ameliorated the enzyme level versus $\mathrm{CCl} 4$ intoxicated group $(\mathrm{P}<0.001)$.
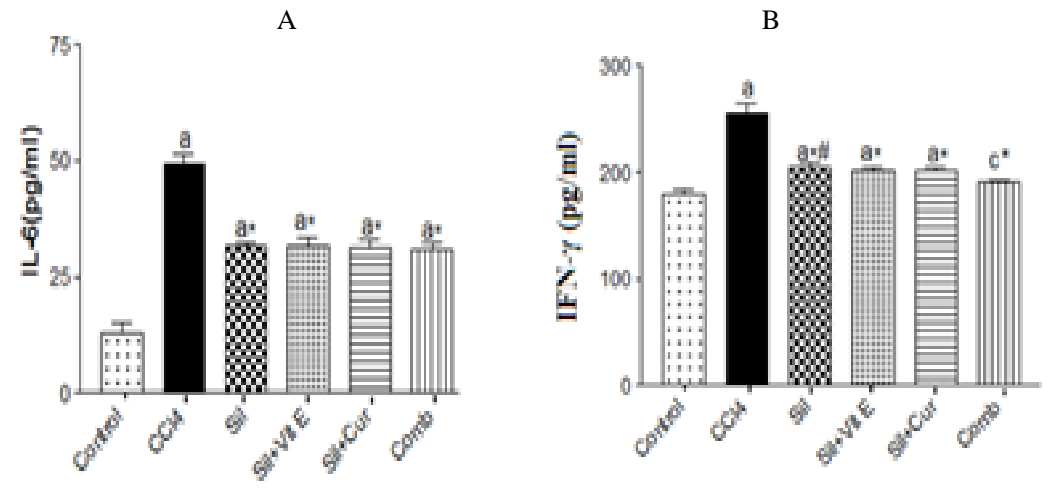

The current result also showed that administration of $\mathrm{CCl} 4$ to rats, significantly elevated the activity level of the serum liver function index, ALT, with respect to normal rats $(\mathrm{P}<0.001)$. Treatment of rats with silymarin alone or in a combination with vitamin $\mathrm{E}$ or curcumin, markedly ameliorated the elevation of serum ALT versus $\mathrm{CCl} 4$ intoxicated rats (Fig. 4). Combined administration of the three agents was the effective one in reducing the activity of the serum liver enzyme in $\mathrm{CCl} 4$ intoxicated rats.

Figure 2 - Effect of silymarin alone or in a combination with Vit E and/or curcumin on serum levels of IL-6 (A), IFN- $\gamma(\mathrm{B})$ and VEGF (C) in CCl4-intoxicated rats. Values are mean \pm S.D $(\mathrm{n}=10)$. ${ }^{\mathrm{a}} \mathrm{P}<0.001$ and ${ }^{\mathrm{c}} \mathrm{P}<0.05$ compared to normal control group, $* \mathrm{P}<0.001$ compared to CCl4-intoxicated group, ${ }^{\#} \mathrm{P}<0.05$ compared to Sil+Vit E+Cur (Comb) group, using ANOVA followed by Tukey-Kramer as post ANOVA test.

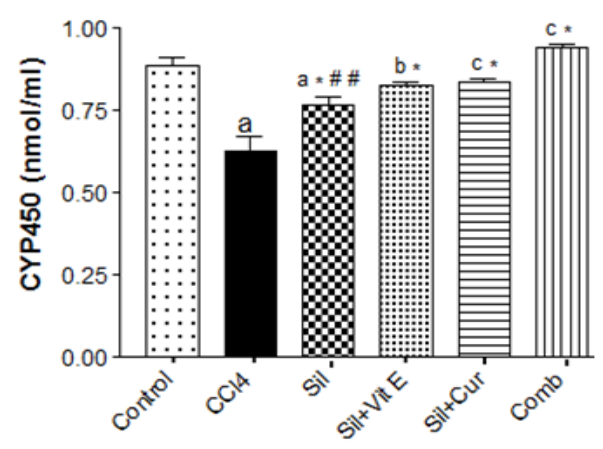

Figure 3 - Effect of silymarin alone or in combination with Vit $\mathrm{E}$ and/or curcumin on cytochrome P450 level in livers of CCl4-intoxicated rats. Values are mean \pm S.D $(n=10) .{ }^{\mathrm{a}} \mathrm{P}<0.001,{ }^{\mathrm{b}} \mathrm{P}$ $<0.01$ and ${ }^{\mathrm{c}} \mathrm{P}<0.05$ compared to normal control group, $* \mathrm{P}<0.001$ compared to $\mathrm{CCl} 4$ intoxicated group, \#\#P $<0.01$, compared to Sil+VitE+Cur (Comb) group, using ANOVA followed by Tukey-Kramer as post ANOVA test.

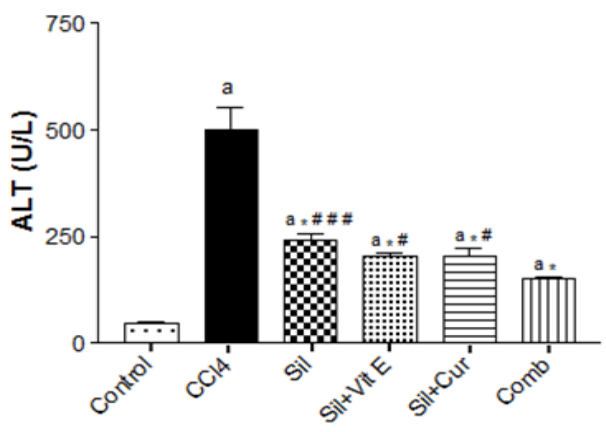

Figure 4 - Effect of silymarin alone or in a combination with Vit $\mathrm{E}$ and/or curcumin on serum alanine transaminase in CCl4-intoxicated rats. Values are mean \pm S.D $(n=10) .{ }^{a} \mathrm{P}<$ 0.001 compared to normal control group, ${ }^{*} \mathrm{P}$ $<0.001$ compared to CCl4-intoxicated group, \#\#\# < 0.001, and \#P $<0.05$ compared to Sil+VitE+Cur (Comb) group, using ANOVA followed by Tukey-Kramer as post ANOVA test. 


\section{Histopathological evaluation}

The histopathology of liver sections of $\mathrm{CCl} 4$ intoxicated groups and control one are presented in Figure 5 (A-F) Normal liver section showed little collagen fiber especially in the portal area (Fig. 5 A). The hepatic toxicity induced by $\mathrm{CCl} 4$ in all studied animal sections demonstrated large patches of fibrous tissue (Fig. 5B). Small patches of collagen deposition were shown in sections of rat livers suffered from hepatic toxicity and received silymarin alone (Fig. 5 C). Treatment with silymarin and vitamin $\mathrm{E}$ showed a decrease of fibrous tissue deposition, but still there are scattered areas of collagen deposition in the portal area which are more than the normal (Fig. 5D). Sections of rat livers suffered from liver toxicity, and treated with both silymarin and curcumin showed little fibrosis (Fig 5E). Histopathological observation of the liver sections of rats suffering from liver toxicity but received a combination of silymarin, vitamin $\mathrm{E}$ and curcumin showed apparently normal collagen distribution within liver tissues (Fig. 5F).
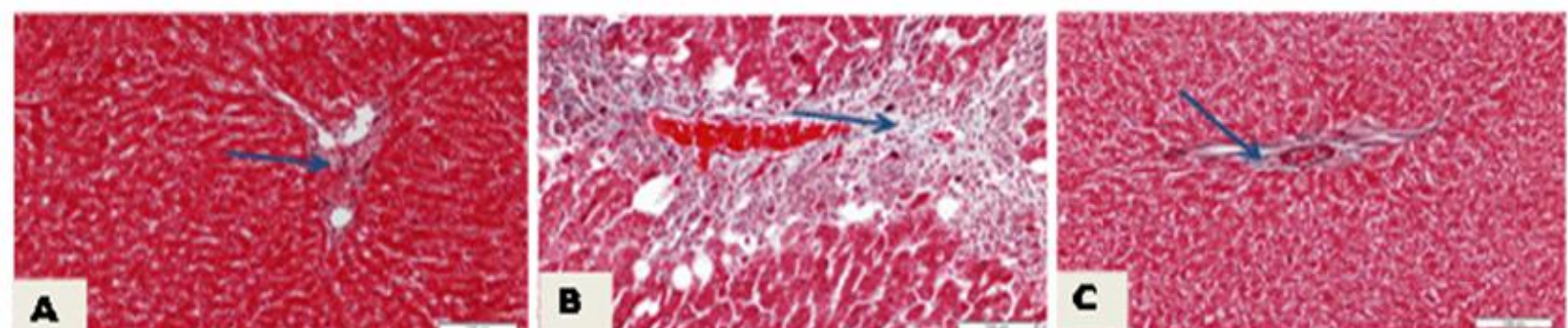

A

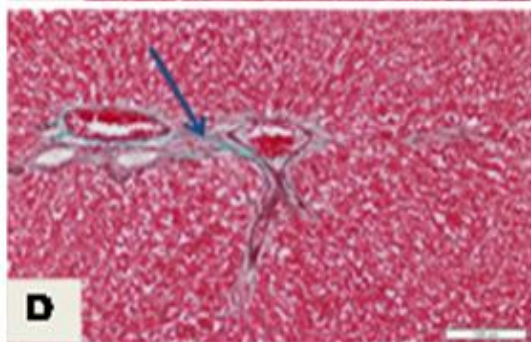

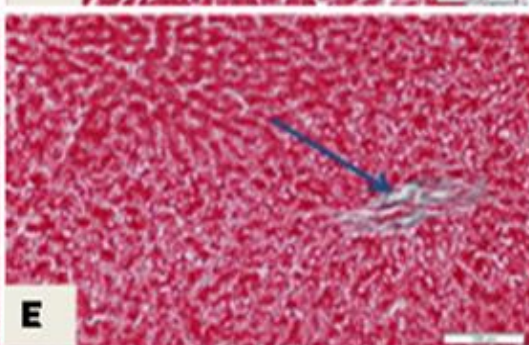

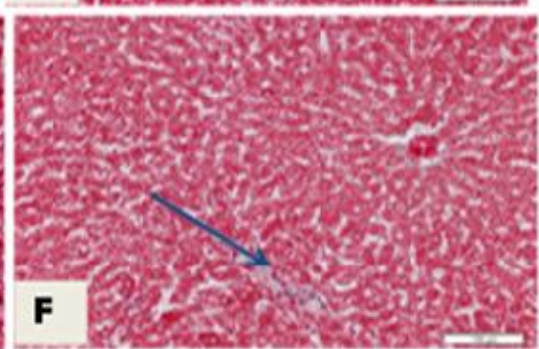

Figure 5 - Light photomicrograph of rat livers stained with Masson's trichrome; scale bar=100 $\mu \mathrm{m}$ in which (A) showing normal little collagen fibers specially in the portal area (arrow), (B) hepatic toxicity induced by $\mathrm{CCl} 4$, showing large patches of fibrous tissue (arrow), (C) rat livers suffered from hepatic-toxicity and received silymarin, showing small patches of collagen deposition (arrow), (D) livers of rats suffered from liver toxicity but received both silymarin and vitamin E, showing a decrease of fibrous tissue deposition but still there are scattered areas of collagen deposition in the portal area which are more than normal (arrow), (E) livers of rats suffered from hepatic toxicity and received silymarin and curcumin showing also areas of little fibrosis (arrow), while (F) represents hepatic toxicity in rats received a combination of silymarin, vitamin $\mathrm{E}$ and curcumin showing apparently normal collagen distribution within liver tissue.

\section{DISCUSSION}

$\mathrm{CCl}_{4}$ exposure can induce increases in lipoperoxide and free peroxide radical concentrations that are highly reactive and cause injury or necrosis (Miyazaki et al. 2009). In the current study, significant increases in the tail length, DNA\% in the tail and \% tailed was noticed in the liver tissues of $\mathrm{CCl} 4$ treated rats as compared to control ones. The results suggested that the hepatic damaging effect of $\mathrm{CCl} 4$ may due to the degradation of DNA of liver tissue of rats by generation of free radicals (Makni et al. 2012). According to Marnett et al. (2000), the product of lipid peroxidation react with DNA to form adducts, the mutagenic pirimedopurinone adduct of deoxyguanosine. Like other macromolecules such as lipids and proteins, nucleic acids are also attacked by free radicals to cause oxidative DNA damage. Administration of silymarin alone or in a combination with vitamin $\mathrm{E}$ and/or curcumin to $\mathrm{CCl} 4$-intoxicated rats, effectively attenuated the 
deviation in the above markers of liver DNA damage. The combination of the three agents was the potential one as it ameliorated these markers around their normal levels. Previous study documented that silymarin possesses substantial protective effect against DNA damage and apoptosis induced by the environmental pollutant benzo (a) pyrene (Perumal et al. 2012). Also, the effectiveness of vitamin $\mathrm{E}$ in quenching free radicals and functioning as a membrane stabilizer was also documented (Zhang et al. 2014).

It was shown that liver 8-OHdG levels increased significantly in rats intoxicated with $\mathrm{CCl} 4$ as compared to the control rats. Azad et al. (2008) indicated that the imbalanced reactive oxygen species formation results in oxidative modification of macromolecule and subsequently genomic instability, which may explain the elevation in 8OHdG level. Liver 8-OHdG level was greatly diminished by the administration of silymarin alone or in a combination with vitamin $\mathrm{E}$ and/or curcumin as compared to rats intoxicated with CCl4. Restoration in the level of $8-\mathrm{OHdG}$ by the used agents may result from the change in the tissue redox system by scavenging the free radicals and improving the antioxidant status of the liver during $\mathrm{CCl} 4$ hepatotoxicity (Adel 2006).

In the present stud, the apoptosis marker, caspase 3 , was markedly increased in livers of $\mathrm{CCl} 4$ treated rats as compared to control group, suggesting that apoptosis might contribute to the DNA damage induced by CCl4 toxicity (Karakus et al. 2011). The intake of silymarin alone or in a combination with vitamin $\mathrm{E}$ and/or curcumin to $\mathrm{CCl} 4$-intoxicated rats, markedly down-regulated the increase in liver caspase 3. This result may support the beneficial effect of the three agents in modulating hepatotoxicity induced by CCl4. This result is in agreement with Patel et al. (2010) who documented that silymarin reduced apoptotic cell death associated with hepatotoxicity.

The present study revealed that $\mathrm{CCl} 4$ intoxication caused marked increases in the levels of the immunological pro-inflammatory biomarkers, TNF- $\alpha$ and CRP, in the rat liver tissues as well as in the pro-inflammatory cytokines, IFN- $\gamma$ and and IL-6, in rat sera compared with the normal group. The increase in the inflammatory markers may be due to up regulation of $\mathrm{NF}-\kappa \mathrm{B}$, which is required for the induction of pro-inflammatory cytokines, such as IL-1ß, TNF- $\alpha$ and IL-6(Ali et al. 2004).

TNF- $\alpha$ is a key mediator of the immune and inflammatory responses and controls the expression of the inflammatory gene network. Therefore, the overproduction of TNF- $\alpha$ contributes significantly to the pathological complications observed in many inflammatory diseases (Feng et al. 2005) .Similarly, hepatic injury is associated with the up regulation of TNF$\alpha$ and IL-6 mRNA expression that was observed in the CCl4 group (AlSaid et al. 2015).

Silymarin alone or in a combination with vitamin E or curcumin treatment significantly reduced the levels of these biomarkers in $\mathrm{CCl} 4$ intoxicated rats. However, the combination of the three agents resulted in restoration of the inflammatory markers near to the level of the normal control. These results indicated that silymarin, vitamin $\mathrm{E}$ and curcumin could be suppressed the inflammatory liver injury caused by $\mathrm{CCl} 4$, which may be related to their anti-inflammatory and immunomodulatory beneficial actions.

The present study also demonstrated a significant increase in the angiogenic factor VEGF in the sera of rats intoxicated with CCl4. Similar result was obtained by Shi et al. (2009). Also, previous data stated that the expression of various inflammatory tissue factors, cytokines, and chemokines stimulate VEGF synthesizing cells such as platelets, immune cells, and inflammatory cells. Increased tissue factors expression is thought to play a significant role in the development of multi-organ system failure in acute injury (Verheul et al. 2000). Ingestion of Silymarin alone or in a combination with vitamin $\mathrm{E}$ and/ or curcumin effectively decreased the serum VEGF level in $\mathrm{CCl} 4$ intoxicated rats compared to $\mathrm{CCl} 4$ intoxicated untreated animals. The combination of the three agents was the most beneficial in modulating this marker toward the normal level, suggesting their anti-angiogenic potential action (Park et al. 2010; Deep et al. 2012). The antiangiogenic effect of silymarin alone or in a combination with vitamin $\mathrm{E}$ and /or curcumin might be attributed to their rapid inhibitory action on the secretion of the primary angiogenic factor, VEGF. Jiang et al. (2000) reported that silymarin has antiangiogenic activity. Additionally, silybin (the main active constituent of silymarin) decreased the expression of hypoxia inducible factor-1 $\alpha$ (HIF-1 $\alpha$ ) and inducible nitric oxide synthase (iNOS) that induce angiogenesis (Raina et al. 2008).

Intoxication of $\mathrm{CCl} 4$ significantly decreased the level of P4502E1 in the liver tissues .Treatment of rats with silymarin alone or in a combination with vitamin $\mathrm{E}$ and/or curcumin, significantly increase 
the level of P4502E1 in all studied groups. The potential therapeutic ability of silymarin alone or in a combination with the studied agents (vitamin $\mathrm{E}$ and/or curcumin) against CCl4-induced liver injury in rats may contribute to their antioxidant, anti-inflammatory and anti-apoptotic properties (Guangwei et al. 2010).

Some studies suggested that curcumin can limit ROS production from microsomes, and activates NF-E2-related factor 2 (Nrf2) translocation to the nucleus, where it activates the expression of antioxidant enzymes (Charoensuk et al. 2011). In this study it is also evidenced by curcumin and vitamin $\mathrm{E}$ treatment significantly restoring all the studied parameters. It is assumed that administration of silymarin, vitamin $\mathrm{E}$ and curcumin co-operatively act on ROS induced by CCl4. Also, it was found that curcumin or vitamin $\mathrm{E}$ alone have been shown positive effect, however they are less effective compared with the combined administration of the two agents (Venkatanarayana et al. 2013).

Intoxication of $\mathrm{CCl} 4$ significantly elevated serum ALT. Treatment of rats with silymarin alone or silymarin and vitamin E or Curcumin significantly reduce the elevation of ALT in all studied groups. Such elevation of ALT suggested that $\mathrm{CCl} 4$ toxicity was able to reach the liver and induce a detectable damage. Patrick-Iwuanyanwu et al. (2007) attributed the elevation of ALT to the release of the enzyme from the cytoplasm into the blood circulation after rupture of the plasma membrane and cellular damage. Administration of silymarin, vitamin $\mathrm{E}$ and/or curcumin, significantly reduced the activity of liver enzyme ALT in CCl4 intoxicated rats, a finding which is consistent with those shown by Pradeep et al. (2007)

Fibrosis induced by $\mathrm{CCl} 4$ toxicity in rat livers was also evaluated by a histological study .In general, $\mathrm{CCl} 4$ intoxication produced a marked increase in collagen deposition especially in the portal area. Marked disruption of the structure of hepatocytes was also noticed. Therapy with silymarin without or with vitamin $\mathrm{E}$ or curcumin showed marked decrease in collagen deposition and regenerative hepatocytes, only slightly affected normal architecture of hepatocyte cords with a few areas of discontinuity. In contrary, histological observations depicts that silymarin along with vitamin E and curcumin showed apparently normal collagen distribution and normal liver architecture. The modulating effect of the used agents on collagen liver deposition may indicate the anti- fibrotic benefit of the used agents. Therefore, it is assumed that combined administration of silymarin, vitamin $\mathrm{E}$ and curcumin co-operatively act on ROS induced liver damage in response to $\mathrm{CCl} 4$ toxicity. The results of the present study supported with the earlier findings suggested that curcumin combination with vitamin $\mathrm{E}$ may be considered as potentially combating oxidative stress and nephrotoxicity induced by CCl4 (Venkatanarayana et al. 2012). The anti-inflammatory effects of silymarin are also based on multiple activities including mast cell stabilization, inhibition of neutrophil migration, Kupffer cell inhibition, inhibition of leukotrienes, and prostaglandin formation (Song et al. 2006). In addition, it is likely that the hepatoprotective effect of silymarin is related to prevention of hypoxia in hepatic fibrogenesis (Song et al. 2006). Recent study supported the use of silymarin as hepatoprotective remedy; it has been used for the treatment of numerous liver disorders characterized by functional impairment or degenerative necrosis. Its hepatoprotective activity is unique and acts in different ways, including antioxidant and anti-inflammatory activities, cell permeability regulator and membrane stabilizer, stimulation of liver regeneration and inhibition of deposition in collagen fibers, which may lead to cirrhosis (Bahmani et al. 2015).

\section{CONCLUSION}

Our study suggests that combined administration of urcumin and vitamin $\mathrm{E}$ with silymarin may be considered as potentially combating liver damaged induced by $\mathrm{CCl} 4$ due to their anti-inflammatory, antiangiogenic and antioxidant effects. The study suggests that silymarin, vitamin $\mathrm{E}$ and/or curcumin may prove to be an effective therapeutic agents in toxin induced liver injuries, such as those induced by $\mathrm{CCl} 4$ and other hepato-toxins.

\section{ACKNOWLEDGEMENTS}

This research project was supported by a grant from the 'Research Center of the Center for Female Scientific and Medical Colleges', Deanship of Scientific Research, King Saud University. 


\section{REFERENCES}

Adel RA. Alpha-lipoic acid counteracts the promoted oxidative DNA damage in the liver of septic rats. Saudi Pharm J. 2006; 14(2): 82-99.

Ali S, Mann D. ASignal transduction via the NF-jB pathway: a targeted treatment modality for infection, inflammation and repair. Cell Biochem Funct. 2004; 22: 67-79.

AlSaid M, MothanaR, Raish M, Al-Sohaibani M, AlYahya M, Ahmad A, et al. Evaluation of the Effectiveness of Piper cubeba Extract in the Amelioration of CCl4-Induced Liver Injuries and Oxidative Damage in the Rodent Model. Biomed Res Int. 2015; 2015: 1-11

Asami S, Hirano T, Yamaguchi R, Tomioka Y, Itoh H, Kasai H. Increase of a type of oxidative DNA damage, 8-hydroxyguanine and its repair activity in human leukocytes by cigarette smoking. Cancer Res. 1996; 56: 2546-2549.

Azad N, Rojanasakul Y, Vallyathan V. Inflammation and lung cancer: roles of reactiveoxygen/nitrogen species. J Toxicol Environ Health B Crit Rev. 2008; 11(1): 1-15.

Bahmani M, Shirzad H, Rafieian S, Rafieian-Kopaei M. Silybum marianum: Beyond Hepatoprotection. JEvid Based Complementary Altern Med. 2015 (In press)

Daniel S, Limson JL, Dairam A, Watkins GM , Daya S. Through meta binding, curcumin protects against lead- and cadmium-induced lipid peroxidation in rat brain homogenates and against lead-induced tissue damage in rat brain. $J$ Inorg Biochem. 2004; 98: 266-275.

Deep G, Gangar SC, Rajamanickam S, Raina K, Gu M, Agarwal C, et al. Angiopreventive efficacy of pure flavonolignans from milk thistle extract against prostate cancer: targeting VEGF-VEGFR signaling. PLoS One. 2012; 7(4): e3463

Farghali H, Kamenikova L, Hynie S, Kmonickova E. Silymarin effects on intracellular calcuim and cytotoxicity: a study in perfused rat hepatocytes after oxidative stress injury. Pharmacol Res. 2000; 41: 231-237.

Feng RT, Lu YJ, Bowman LL, Qian Y, Castranova V, Ding M. Inhibition of activator protein-1, NF-kappa $\mathrm{B}$, and MAPKs and induction of phase 2 detoxifying enzyme activity by chlorogenic acid. J Biol Chem. 2005; 280: 27888-27895.

Flora K, Hahn M, Rosen H, Benner K. Milk thistle (Silybum marianum) for the therapy of liver disease. Am J Gastroenterol. 1998; 93:139-14329.

Guangwei X, Rongzhu L, Wenrong X, Suhua W, Xiaowu Z, et al. Curcumin pretreatment protects against acute acrylonitrile-induced oxidative damage in rats. Toxicol. 2010; 267 (1-3): 140-146.
Jiang C, Agarwal R, Lü J. Anti-Angiogenic Potential of a Cancer Chemopreventive Flavonoid Antioxidant, Silymarin: Inhibition of Key Attributes of Vascular Endothelial Cells and Angiogenic Cytokine Secretion by Cancer Epithelial Cells. Biochem Biophys Res Commun. 2000; 276(1):371-378.

Karakus E, Karadeniz A, Simsek N, Can I, Kara A, Yildirim S, et al. Protective effect of Panax ginseng against serum biochemical changes and apoptosis in liver of rats treated with carbon tetrachloride $(\mathrm{CCl} 4)$. J Hazard Mater. 2011; 195: 208-213

Karima M. Moawad. (confirmar) Possible prophylactic effects of vitamin $\mathrm{E}$ or lycopene treatment on renal toxicity induced by $\mathrm{CCl} 4$ administration in albino rats. World Journal of Zoology. 2007; 2 (2): 19-28.

Lee A, East J, Balgaug P. Interactions of insecticides with biological membranes. Pesticide Science. 1991; 32:317-327.

Li CC, Hsiang CY, Wu SL, Ho TY. Identification of novel mechanisms of silymarin on the carbon tetrachloride-induced liver fibrosis in mice by nuclear factor-jB bioluminescent imagingguided transcriptomic analysis. Food Chem Toxicol. 2012a; 50 (5):1568-1575.

Makni M, Chtourou, Y, Garoui EM, Boudawara T, Fetoui H. Carbon tetrachloride-induced nephrotoxicity and DNA damage in rats: protective role of vanillin. Hum Exp Toxicol. 2012; 31(8): 844852.

Manibusan MK, Odin M, Eastmond DA. Postulated carbontetrachloride mode of action: a review. $J$ Environ Sci Health C Environ Carcinog Ecotoxicol. Rev 2007; 25: 185-209.

Marnett JL. Oxyridicals and DNA damage. Carcinogenesis. 2000, 21:61-70.

Mechtcheriakova D, Schabbauer G, Lucerna M, Clauss M, De Martin R, Binder BR, et al. Specificity, diversity, and convergence in VEGF and TNF-alpha signaling events leading to tissue factor up-regulation via EGR-1 in endothelial cells. FASEB J. 2001; 15: 230-242.

Muriel P, Mourelle M. Prevention by silymarin of membrane alterations in acute $\mathrm{CCl} 4$ liver damage. $J$ Appl Toxicol. 1990; 10: 275-279.

Naik RS, Mujumdar AM, Ghaskadbi S. Protection of liver cells from ethanol cytotoxicity by Curcumin in liver slice culture in vitro. $J$ Ethnopharmacol. 2004; 95: 31-37.

Nakae D, Mizumoto Y, Kobayashi E, Noguchi O, Konishi Y. Improved genomic/nuclear DNA extraction for 8-hydroxydeoxyguanosine analysis of small amounts of rat liver tissue. Cancer Lett .1995; 97:233-239.

Olive PL, Banath JP, Durand RE. Heterogeneity in radiation induced DNA damage and repair in tumor and normal cells using the "Comet" assay. Radiat Res.1990; 122: 86-94. 
Park SY, Jang WJ, Yi EY, Jang JY, Jung Y, Jeong JW, et al. Melatonin suppresses tumor angiogenesis by inhibiting HIF-1alpha stabilization under hypoxia. $J$ Pineal Res. 2010; 48 (2): 178-184.

Patel N, Joseph C, Corcoran G.B., Ray S.D. Silymarin modulates doxorubicin-induced oxidative stress, Bcl$\mathrm{xL}$ and p53 expression while preventing apoptotic and necrotic cell death in the liver. Toxicol Appl Pharmacol .10; 245 (2): 143-15

Patrick-Iwuanyanwu KC, Wegwu MO, Ayalogu EO. Prevention of CCl4-Induced Liver Damage by Ginger, Garlic and Vitamin E. Pak J Biol Sci. 2007; 10: 617-621.

Perumal VK, Muruganantham S, Subramanian M, Shunmugiah KP, Kasi PD. Silymarin attenuates benzo(a)pyrene induced toxicity by mitigating ROS production, DNA damage and calcium mediated apoptosis in peripheral blood mononuclear cells (PBMC). Ecotoxicol Environ Saf. 2012; 86: 79-85.

Planagum A, Claria J, Miquel R, Lopez-Parra M, Titos E, Masferrer JL, et al. The selective cyclooxygenase2 inhibitor SC-236 reduces liver fibrosis by mechanisms involving non-parenchymal cell apoptosis and PPAR gamma activation. FASEB J. 2005; 19: 1120-1122.

Polyak SJ, Morishima C, Shuhart MC, Wang CC, Liu $\mathrm{Y}$, Lee DY. Inhibition of T-cell inflammatory cytokines, hepatocyte NF-kappaB signaling, and $\mathrm{HCV}$ infection by standardized Silymarin. Gastroenterol. 2007; 132 (5): 1925-1936.

Pradeep K, Mohan CV, Gobianand K, Karthikeyan S. Silymarin modulates the oxidant antioxidant imbalance during diethylnitrosamine induced oxidative stress in rats. Eur J Pharmacol. 2007; 10, 560(2-3): 110-116.

Raina K, Rajamanickam S, Singh RP, Deep G, Chittezhath M, Agarwal R. Stage-specific inhibitory effects and associated mechanisms of silibinin on tumor progression and metastasis in transgenic adenocarcinoma of the mouse prostate model. Cancer Res. 2008; 68(16):6822-6830.

Shi H, Dong L, Bai Y, Zhao J, Zhang, Y, Zhang L. Chlorogenic acid against carbon tetrachlorideinduced liver fibrosis in rats. Eur J Pharmacol. 2009; 623 (1-3): 119-124

Singh NP, McCoy MT, Tice RR, Schneider EL. A simple technique for quantitation of low levels of DNA damage in individual cells. Exp Cell Res. 1998; 175: 184-191.
Song Z, Deaciuc I, Song M, Lee DY, Liu Y, Ji X, et al. Silymarin protects against acute ethanol-induced hepatotoxicity in mice. Alcohol Clin Exp Res. 2006; 30(3):407-413.

Sreepriya M, Bali G. Effects of Administration of embelin and curcumin on lipid peroxidation, hepatic glutathione antioxidant defense and hematopoietic system during nitrosodiethylamine/phenobarbitalinduced hepato carcinogenesis in wistar rats. Mol Cell Biochem. 2006; 284(1-2): 49-55.

Vaculova A, ZhivotovskyB. Caspases: Determination of their activities in apoptotic cells. Methods Enzymol. 2008; 442: 157-181.

Venkatanarayana G, Sudhakara G, Sivajyothi P, Indira $P$. Protective effects of curcumin and vitamin $E$ on Carbon tetrachloride-induced nephrotoxicity in rats. EXCLI Journal. 2012; 11: 641-650.

Venkatanarayana G, Sudhakara G , Rajeswaramma K , Indira P. Combined effect of curcumin and vitamin $\mathrm{E}$ against CCl4induced liver injury in rats. AJLS. 2013; 1(3): 117-124.

Verheul HM, Jorna AS, Hoekman K, BroxtermanHJ, Gebbink MF, Pinedo HM. Vascular endothelial growth factors stimulated endothelial cells promote adhesion and activation of platelets. Blood. 2000; 96: 4216-4221.

Wai S, Karim R, Kitano M, Sukata T, Min W, Morimura K, et al. Role of oxidative DNA damage caused by carbon tetrachloride-induced liver injury enhancement of MeIQ-induced glutathione Stransferase placental form-positive foci in rats. Cancer Lett. 2002; 179 (1): 15-24.

Weber LW, Boll M, Stampfl A. Hepatotoxicity and mechanism of action of haloalkanes: carbon tetrachloride as a toxicological model. Crit Rev Toxicol. 2003; 33(2): 105-136.

Wellington K, Jarvis B. Silymarin: a review of its clinical properties in the management of hpatic disorders. BioDrugs. 2001; 15: 465-489.

Yachi R, OsamuI, garashiO, Kiyose C. Protective effect of vitamin $\mathrm{E}$ against carbon tetrachloride induced fatty liver in rats. J Clin Biochem Nutr. 2010; 47: 148-154.

Zhang J, Xu L, Zhang L, Ying Z, Su W, Wang T. Curcumin attenuates D-galactosamine/ lipopolysaccharide-induced liver injury and mitochondrial dysfunction in mice. J Nutr. 2014; 144(8):1211-1218. 